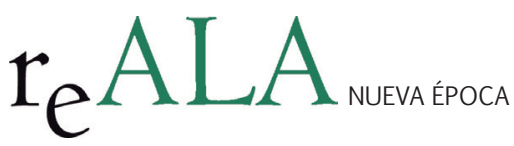

REALA, n 3, enero-junio 2015 ISSN: 1989-8975

DOI: http://dx.doi.org/10.24965/reala.voi3.10251

\title{
Descentralización y autonomía Local. Reforma de las competencias municipales en España y Perú
}

\author{
Mónica Tesalia Valcárcel Bustos \\ Asociación Iberoamericana de Estudios para el Desarrollo \\ tesaliavalcarcel@yahoo.com
}

\section{Resumen}

España y Perú, desde finales del 70, vienen implementado procesos de descentralización hacia los gobiernos sub-nacionales, a fin de hacer más eficientes las tareas del Estado. El nivel municipal no resulta ser más avanzado que el gobierno regional, pero goza de autonomía local y una esfera de competencias. En los últimos años, la regulación en materia local ha sido cuestionada por falta de claridad de las competencias locales, ya que se han registrado casos de duplicidad de funciones con otros niveles de gobierno. A través de este estudio se analizan, a nivel comparativo, el modelo de descentralización y la duplicidad de competencias locales que ha dado lugar a las reformas emprendidas por ambos países.

Palabras clave

Descentralización, autonomía local, competencias locales y gobiernos locales.

\section{Decentralization and local autonomy. Reform of municipal powers in Spain and Peru}

\section{Abstract}

Spain and Peru, from the late 70 's, are implemented decentralization to sub-national governments in order to streamline the work of the State. The municipal level is not being more advanced than the regional government, but have local autonomy and sphere of competence. In recent years, regulating local matters has been challenged by lack of clarity in local competitions, as there have been cases of duplication of functions with other levels of government. Through this study are discussed, a comparative level, the model of decentralization and local duplication of powers has led to reforms undertaken by both countries.

\section{Keywords}

Decentralization, local autonomy, local skills and local governments. 


\section{SUMARIO}

I. Introducción.- II. El modelo de descentralización hacia los gobiernos locales.-1. La descentralización y el gobierno local.- 1.1. El Estado Autonómico y los Entes Locales en España.- 1.2. El reciente despegue de la descentralización en Perú.- 2. Configuración jurídico-institucional del Gobierno Local.2.1. Los Entes Locales en España.- 2.2. Las Municipalidades en Perú.- 3. Garantía constitucional de la Autonomía local.- 3.1. Reducción de la autonomía local en España.- 3.2. Límites a la autonomía de los gobiernos municipales en Perú.- 4.- Duplicidad de competencias y reformas al régimen local.4.1. Reformas a las competencias locales por reducción del gasto público en España.- 4.2. Reformas pendientes por falta de concordancia normativa en Perú.- III. Conclusiones.- Bibliografía.

\section{INTRODUCCION}

En Europa y América Latina, a partir del fracaso del centralismo como forma de gobierno, en diferentes momentos y contextos históricos, se iniciaron procesos de descentralización que tuvieron un gran aporte al retorno de la democracia y la existencia de distintos niveles de gobierno. En la actualidad, muchos gobiernos han optado por descentralizar el Estado. Perú y España, a pesar de ubicarse en continentes diferentes, han coincidido en optar por este modelo de organización y dotar a sus gobiernos locales de autonomía. De esta forma, el proceso de descentralización ha evolucionado y se han dado importantes progresos hacia la autonomía local, aunque con distintos grados de profundidad, entre ellos el reconocimiento de competencias locales por la Constitución y leyes especiales. Pese a lo anterior, en los últimos tiempos, ambos países han determinado que existe una falta de delimitación de las competencias locales, para lo cual han implementado importantes reformas. Para conocer los efectos de estas últimas en la descentralización y autonomía local, se hace un análisis comparativo de ambos modelos.

\section{EL MODELO DE DESCENTRALIZACIÓN HACIA LOS GOBIERNOS LOCALES}

\section{La descentralización y el gobierno local}

La descentralización involucra la transferencia de poder desde el nivel central hacia los niveles regionales y municipales. Este modelo se encuentra implantado en España y Perú. En este apartado se hace una revisión sobre el estado de la descentralización en ambos países, con especial énfasis en los gobiernos locales.

\subsection{El Estado Autonómico y los Entes Locales en España}

La Constitución de 1978 determina el cambio del aparato político y administrativo centralista hacia uno descentralizado. Esta Carta Constitucional reconoce la existencia de Comunidades Autónomas y Corporaciones Locales dotadas de autonomía propia, como partes integrantes de la estructura territorial del Estado'. No obstante, según algunos autores, los municipios no fueron actores partícipes del proceso de descentralización política, inaugurado por el Constituyente, sino únicamente agentes de una mera descentralización administrativa, por tanto, la descentralización solo estuvo dirigida a dos actores: Estado y Comunidades Autónomas².

Los caracteres actuales del Estado Autonómico producto del desarrollo normativo y jurisprudencial, presentan las siguientes características: a) es un Estado políticamente descentralizado, como una especie del Estado compuesto; b) Esa descentralización política (respecto de los poderes legislativo y ejecutivo) ha alcanzado un nivel equiparable al máximo que sólo tienen algunos Estados Federales; c) con excepción de una pequeña parte del territorio (Ceuta y Melilla), la descentralización política es general y simétrica; d) la articulación jurídica de la estructura territorial del Estado no se contiene únicamente en la Constitución, sino en un bloque normativo, formado por la Constitución y diecinueve Estatutos de Autonomía³.

Pese a estos avances de la descentralización del Estado Autonómico, algunos autores, lo consideran un modelo inacabado, porque desde la entrada en vigor de la Constitución de 1978, se dejó en un total rezago a los gobiernos locales. De esta forma, creen que hacía falta una segunda descentralización hacia los gobiernos locales que viniera de parte de las Comunidades Autónomas

Desde la dación de la Ley Reguladora de las Bases de Régimen Local -LRBRL, de 1985, se han dado distintas iniciativas con miras hacia la segunda descentralización, principalmente, con el objetivo de definir las competencias

CLAVERO ARÉVALO, M. F. (1999): 49.

CAAMAÑO DOMÍNGUEZ, F. (2004): 162.

ARAGON REYES, M., (2006): 87-88.

ÁLVAREZ, J.L. y MOLERO, J.C., (2011): 34.

REALA, n 3, enero-junio 2015, ISSN: 1989-8975 - DOI: http://dx.doi.org/10.24965/reala.v0i3.10251 
locales, sin embargo no prosperaron. La última reforma que aborda el tema competencial es la reciente Ley 27/2013, de 27 de diciembre, denominada de “racionalización y sostenibilidad de la Administración Local”. Su fundamento, contenido en el preámbulo, se sustenta, principalmente, en el principio rector de la estabilidad presupuestaria regido bajo la LO 2/2012, del 27 de abril, a raíz de la crisis económica que soporta España. Esta Ley plantea tres objetivos de ajuste: (i) clarificar las competencias locales, para evitar duplicidades con otras administraciones del Estado; (ii) racionalizar la estructura orgánica de la administración local, de conformidad con los principios de eficiencia, estabilidad y sostenibilidad financiera; y, (iii) garantizar el control financiero y presupuestal de forma rigurosa. En este estudio, sólo se abordará el primer objetivo por ser el tema que interesa analizar a nivel comparativo.

El legislador se propone "clarificar las competencias", porque considera que en el modelo competencial anterior no estaban del todo delineadas, por lo que los gobiernos locales ejercían muchas actividades y servicios públicos, aun cuando estos no estuvieran contemplados dentro del ámbito de sus competencias. Esta situación, de acuerdo al preámbulo de la Ley 27/2013, generó problemas y dio lugar, entre otros, al solapamiento de competencias locales con otros niveles de gobierno, prestación de servicios locales sin contar con el título competencial respectivo e insuficiencia de recursos para cubrir dichos servicios. Cuestiones que ha generado una difuminación de responsabilidades de los gobiernos locales y confusión de competencias con otros niveles de gobierno; y, una disfuncionalidad entre el modelo competencial y las finanzas locales. Para resolver estas cuestiones el Estado ha optado por precisar las competencias locales diferenciándolas de las que corresponden a otros niveles de gobierno. Pese a sus buenas intenciones, esta reforma es calificada por algunos expertos de fallida porque podría vulnerar la autonomía local5. Un mayor análisis de sus fundamentos se tratará más adelante, en el apartado referido a esta temática.

\subsection{El reciente despegue de la descentralización en Perú}

El Estado peruano, históricamente, se ha caracterizado por tener un alto grado de centralización. Sin embargo, durante toda su vida independiente, ha tenido un carácter unitario, representativo y descentralizado. La actual Constitución Política de 1993, al igual que su antecesora, de 1979, reconoce tres niveles de gobierno (central, regional y municipal) y concibe que el gobierno del Estado peruano es unitario y descentralizado. Los dos conceptos extremos de unidad y descentralización generan una constante tensión. La unidad, encierra una tendencia centrípeta, significa que sólo posee un centro de impulsión política y gubernamental, que se traduce en el poder político del órgano central, cuyas funciones se extienden y abarcan a toda la población y el territorio del Estado. La descentralización, en cambio, corresponde a la idea de transferencia de poder hacia los gobiernos regionales y municipales ${ }^{6}$. Además, la Constitución garantiza a los tres niveles de gobierno autonomía política, administrativa y económica.

Cabe advertir que, durante mucho tiempo, el poder transferido a los gobiernos regionales y municipales fue meramente administrativo. Sólo se delegaban funciones, pero las decisiones se encontraban centralizadas, por tanto, sólo existía una descentralización administrativa. Años más tarde, las regiones exigieron mayor dosis de descentralización. De esa forma, el proceso de descentralización avanzó hacia el traspaso de un mayor número de competencias y recursos hacia los gobiernos regionales, pero en menor medida hacia los gobiernos locales.

El proceso de descentralización en el Perú, ha atravesado por diferentes etapas. La primera, comprendida del 2002 al 2006, se dedica a sentar las bases jurídicas de la descentralización, a partir de la reforma constitucional y la primera elección de los gobiernos regionales, el referéndum regional y la transferencia de funciones a los gobiernos regionales. Entre el 2006 al 2011, se acelera la transferencia de funciones, a través de planes anuales de transferencia de funciones; y se exigen reformas a la descentralización fiscal. La transferencia de funciones a los gobiernos regionales constituye el avance más significativo, a mayo del 2012, se transfirieron el $92.6 \%$ de las funciones previstas en la Ley Orgánica de Gobiernos Regionales? ${ }^{7}$ En cuanto a los Gobiernos Locales, se les transfirieron algunos programas sociales ${ }^{8}$, a través de un proceso de acreditación. El año 2007, el gobierno promovió la municipalización educativa y de salud. La primera, en el nivel inicial y primario, se implementó en 35 municipalidades hasta el 2011, pero el Ministerio de Educación revirtió ese proceso, por las limitaciones en el diseño e implementación 9 . En el ámbito de la salud, se transfirieron competencias a los gobiernos locales para la gestión de la atención primaria de salud ${ }^{10}$, es decir, acciones de planificación, programación, monitoreo, supervisión y

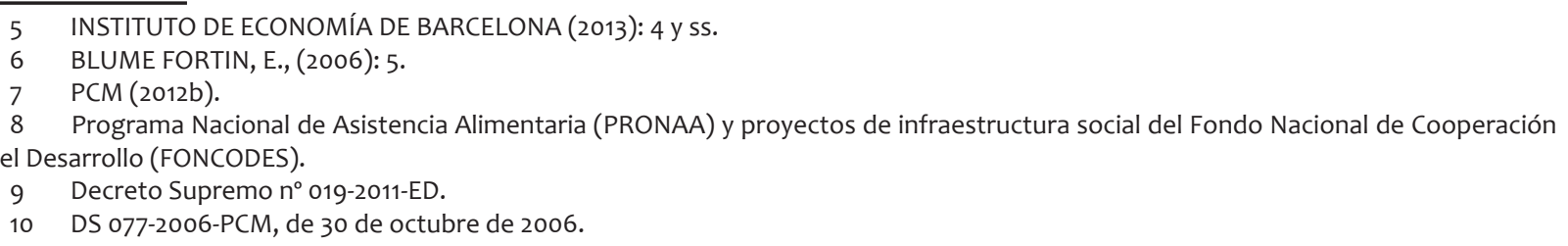


evaluación ${ }^{11}$, así mismo, se implementaron experiencias piloto en varias regiones del país, pero aún no se ha concretado en la transferencia de funciones. Así, a enero de 2012 se había avanzado con el $57 \%$ de la transferencia de los programas y servicios sociales ${ }^{12}$.

Pese a los avances que muestra el proceso de descentralización, uno de los problemas que enfrenta es la falta de claridad de las competencias entre los tres niveles de gobierno, especialmente, entre los niveles locales. Para resolverlo se han planteado propuestas de solución que aún no terminan de dar un resultado positivo. En el ámbito local, las más controvertidas son las competencias compartidas entre las municipalidades provinciales y distritales, por no encontrase claramente establecidas por la Ley Orgánica de Municipalidades. Este aspecto será tratado en otro apartado específico.

En suma, ambos países son unitarios y descentralizados, y poseen tres niveles de gobierno (nacional, regional y local). Sin embargo, España presenta mayor maduración en el proceso de descentralización. El último proceso de descentralización en el Perú, iniciado el 2002, con la reforma constitucional, tiene casi catorce años, por lo que es un proceso joven y sus avances son relativos. En cambio, España, desde el año 1978, tiene más de 35 años de experiencia. La expresión más avanzada de autonomía y descentralización se expresa a través de la conformación de las Comunidades Autónomas.

A pesar de las diferencias encontradas, ambos países comparten una preocupación semejante: la falta de claridad de las competencias locales. En el caso de Perú, debido a que éstas no se encuentran debidamente delimitadas entre los diferentes niveles de gobierno, y a la falta de dimensionamiento de los costes efectivos para el ejercicio de las funciones transferidas. Cuestiones que tienen efectos negativos en la prestación de servicios y las relaciones entre los niveles de gobierno ${ }^{13}$. En España, esta problemática surge a partir de la crisis financiera, que ha dado lugar a la reforma de la Ley Reguladora de Bases del Régimen Local, con el objetivo de reducir los costes que involucra la duplicidad de funciones y recursos.

\section{Configuración jurídico- institucional del Gobierno Local}

Al constituir el Gobierno Local el actor central del presente estudio, conviene analizar su configuración jurídica e institucional en ambos países.

\subsection{Los Entes Locales en España}

La Constitución Española de 1978 establece la organización territorial del Estado y permite diferenciar tres niveles de gobierno: estatal, autonómico y local (Título VIII). En el nivel local se distinguen varias modalidades de Entes Locales. La Ley Reguladora de Bases de Régimen Local (LRBRL), concordante con la norma constitucional, establece el listado de las Entidades Locales, clasificándolas en territoriales y funcionales.

El reconocimiento diferenciado de estas dos categorías de Entidades Locales: territorial y funcional, responde a la diferencia de potestades atribuidas a unas y no a otras. Así, las territoriales cuentan con la integridad de potestades contenidas en el artículo 4.1 de la LRBRL, entre las cuales se encuentran las potestades administrativas en materias tributaria y financiera; mientras que, su acceso de las funcionales no está garantizado, pudiendo ser las Comunidades Autónomas las que determinen de qué potestades disponen.

Las Entidades Territoriales, entre las cuales se hallan el Municipio, la Provincia y la Isla, están generalizadas en toda la nación. En ellas el territorio juega un papel sustantivo, por tanto, no se conciben sin su territorio ${ }^{14}$. Estas entidades, se hallan expresamente contempladas y definidas en el Título VIII del texto constitucional, y en el art. 3.1 de la LRBRL.

Adicionalmente, se reconocen otras Entidades Locales que aparecen contempladas en el art. 3.2 de la LRBRL, las mismas que se han reducido a tres de las cuatro que existían antes de la reforma. Reciben dicho tratamiento: a) Las Comarcas u otras entidades que agrupen varios Municipios, instituidas por las Comunidades Autónomas; b) Las Áreas Metropolitanas; y, c) Las Mancomunidades de Municipios. Las Entidades Inferiores al Municipio han sido suprimidas con la última reforma ${ }^{15}$. De acuerdo a su configuración, todas las entidades locales, anteriormente nombradas, tienen la condición de territoriales, excepto las mancomunidades que cumplen el rol de funcionales como lo prescribe el art. 4.3 LRBRL.

\footnotetext{
11 RESOLUCIÓN MINISTERIAL 1204-2006-SA, de 28 de diciembre de 2006.

PCM (2011): 20-23.

CONGRESO DE LA REPÚBLICA DE PERÚ (2012a): 17-18.

EL CONSULTOR DE LOS AYUNTAMIENTOS Y DE LOS JUZGADOS, (1988): 70-71.

Según la Disposición Transitoria Cuarta de la Ley 27/2013. Sin embargo, conservan su condición de Ente Local, si existían al momento de la entrada en vigor de la Ley 27/2013 y realizan su informe de cuentas al Estado y las CC.AA., al 31 de diciembre, para no ser disueltos.
} 


\subsection{Las Municipalidades en Perú}

Los gobiernos locales se encuentran regulados en la Constitución Política del Estado, por el título IV, correspondiente a la estructura del Estado y el capítulo XIV de la descentralización; por la Ley Orgánica de Municipalidades - LOM (Ley $n^{\circ}$ 27972) y otras normas conexas. Si bien la norma constitucional no los define, sí lo hace la LOM. Son concebidos como las entidades básicas de la organización territorial del Estado. Como tal, constituyen el canal inmediato de participación vecinal en los asuntos públicos. Se reconoce, por tanto, que las Municipalidades son el primer nivel de gobierno que rigen los destinos de una determinada circunscripción territorial. A diferencia de los otros niveles superiores de gobierno (regional y nacional), las municipalidades, al estar más cerca a los vecinos, son reconocidas por su capacidad de conocer de cerca las necesidades de su población, lo que les permite brindar servicios públicos más acordes a las preferencias de los ciudadanos.

Los órganos de gobierno local en Perú, según la norma constitucional y la Ley Orgánica de Municipalidades, están clasificados según su jurisdicción, atendiendo a su ubicación territorial; $y$, conforme al régimen especial que se les asigna cumplir. Por su jurisdicción, se contemplan tres tipos de municipalidades, en función que el territorio se ubique en la provincia, distrito o poblado menor: a) municipalidades provinciales corresponderán al territorio de la provincia y cercado respectivo; b) municipalidades distritales vinculadas al territorio del distrito; c) municipalidades de centros poblados serán determinadas por el Consejo Provincial, a propuesta del nivel distrital. Con régimen especial se encuentran dos tipos de municipalidades, una ubicada en la capital de la república y otra en las zonas de frontera del país: a) La municipalidad metropolitana de Lima, ejercerá sus funciones dentro del ámbito de la provincia de Lima; y, b) las municipalidades de frontera, funcionan en las capitales de provincia y distritos ubicados en la zona de frontera ${ }^{16}$.

Si bien esta agrupación de las municipalidades en dos grupos distintos, podría parecer irrelevante, lo cierto es que existen diferencias importantes entre unas y otras. Las municipalidades provinciales y distritales tienen algunas ventajas prácticas relevantes con relación a su autonomía, de las que no disfrutan las restantes. La Norma Constitucional, en su artículo 194, establece que los órganos provinciales y distritales tienen "autonomía política, económica y administrativa en los asuntos de su competencia", es decir, tienen capacidad de decisión en esas materias. Esto significa que los centros poblados y las municipalidades de frontera quedarían excluidos y, por tanto, no gozarían de autonomía en su quehacer.

De acuerdo a sus características, las municipalidades provinciales y distritales constituyen entidades territoriales, porque, conforme a la doctrina, el territorio juega un papel sustantivo en su configuración, y están generalizadas en todo el territorio del Estado ${ }^{17}$. En cambio, las demás municipalidades, excepto la metropolitana, se podrían considerar entidades funcionales porque son creadas para determinados fines específicos. Así, las municipalidades fronterizas son creadas con fines de integración y los centros poblados para realizar servicios públicos delegados ${ }^{18}$; mientras, la metropolitana, conforme a lo regulado por la Constitución, ejerce sus competencias dentro del ámbito de la provincia de Lima, conforme a las competencias recogidas en la LOM ${ }^{19}$, por lo que se asimila a una municipalidad provincial, pero con determinados privilegios por constituirse la metropolitana en la capital de la república.

En síntesis, en ambos países los Gobiernos Locales están reconocidos por la Constitución y las leyes específicas, como el primer nivel de gobierno. Existen unas entidades territoriales y otras funcionales, pero, sólo las primeras gozan de autonomía local, como las propias normas lo establecen. Por tanto, las entidades que gozan de esta atribución son: los municipios, provincias e islas (España); y, las municipalidades provinciales y distritales (Perú).

\section{Garantía constitucional de la Autonomía local}

La autonomía local es un atributo reconocido a los gobiernos locales tanto de España como de Perú. Sin embargo, tienen sus particularidades que es necesario conocer, para lo cual, a continuación se hace un análisis de cada modelo.

\subsection{Reducción de la autonomía local en España}

La autonomía local es una institución establecida constitucionalmente como principio rector del régimen local. Este reconocimiento ha sido útil para garantizar la existencia de los municipios como entidades locales constitucionalizados y otorgarles un contenido funcional mínimo. Así, la actual Constitución ha puesto de manifiesto la existencia del Ente Local, encargándose la LRBRL en reconocerle las potestades mínimas y la LHL de

\footnotetext{
16 Art. $3^{\circ}$ Ley 27972 , concordante con el Art. $194^{\circ}$ y 198 CPE.

MIR, J., (1987): 200-202.

Art. 133 y 137 de la Ley $n^{\circ} 27972$

Art. 157 y ss., de la Ley $n^{\circ} 27972$
} 
garantizarle los recursos necesarios para que pueda actuar autónomamente. Esta regulación, sin embargo, no logra superar los problemas que arrastra la autonomía local, a raíz de la ausencia constitucional de un elenco concreto de competencias locales. Y, en específico, por la carencia de una lista de competencias propias y específicas de los Entes Locales ${ }^{20}$. Adicionalmente a lo anterior, con la reciente la reforma de la Ley 27/2013, de 30 de diciembre de 2013, se cree que existe una afectación a la autonomía local, como se comentará más adelante.

La Constitución, después de reconocer la organización territorial del Estado en Municipios, Provincias y Comunidades Autónomas, establece que "todas las entidades gozan de autonomía para la gestión de sus respectivos intereses" (Art. 137 CE). Sin embargo, el término "todas", refiriéndose a las Entidades Locales, no incluye a los Entes funcionales, por lo que, se debe entender aplicable únicamente a los Entes territoriales, es decir, a los Municipios, Provincias e Islas. Adicionalmente, cabe advertir que el Art. 140 de la CE garantiza la autonomía únicamente de los Municipios. Por tanto, pareciera existir una incoherencia entre lo establecido por los artículos 137 y 140, ya que, si el primero reconoce la autonomía de todos los entes territoriales, se supone que la misma debiera estar garantizada para todos ellos. Esta ambigüedad es aclarada por la LBRL, indicando que la autonomía es la misma para todas las entidades territoriales, con lo cual, queda claro que las entidades funcionales carecen de ella.

La autonomía local, como se expuso antes, no implica libertad total y absoluta, ya que tiene ciertos límites. El Tribunal Constitucional así lo reconoce en su sentencia 4/1981, de 2 de febrero. Sostiene que es necesario interpretar el art. 137 de la CE y delimitar el ámbito que corresponde al principio de autonomía, con especial referencia a los municipios, para lo cual será necesario relacionar este principio con otros establecidos en la norma constitucional. Esta sentencia aclara que "la autonomía hace referencia a un poder limitado". Sustenta que todo poder tiene sus límites, incluso la soberanía que no se equipara a la autonomía. Concibe que cada organización territorial del Estado, como es el caso de los Entes Locales, tiene una cuota de autonomía pero forma parte integrante del Estado, por lo que el principio de autonomía no puede oponerse al de unidad. En consecuencia, considera que el art. 137 de la CE "exige que se dote a cada ente de todas las competencias propias y exclusivas que sean necesarias para satisfacer el interés respectivo". Los intereses corresponden ya sea al Municipio, Provincia o a la Comunidad Autónoma y el ordenamiento es el instrumento que sirve para que las entidades gestionen sus respectivos intereses. En efecto, de acuerdo a la Constitución, la Ley es la que concreta el principio de autonomía de cada tipo de entes y ubica al Estado en una posición superior, como establecen determinados preceptos de la norma constitucional en relación a los entes locales (art. 148.1.2 $\left.{ }^{\circ}\right)^{21}$. En definitiva, para el Tribunal Constitucional, forma parte de la garantía institucional de la autonomía local constitucionalmente garantizada el derecho de la corporación local a intervenir en aquellos asuntos que afecten a sus intereses de naturaleza local22.

Ojeda sostiene que el límite máximo de la autonomía está constituido por los intereses que no le son propios, por imperio nacional y por la autonomía de las Comunidades Autónomas. Sin embargo, la autonomía local también tiene un límite mínimo que viene establecido por la garantía institucional ${ }^{23}$. Con el afán de clarificar el concepto de autonomía, una posición de la doctrina se interesa por distinguir la autonomía política y la administrativa, atribuidas a las Comunidades Autónomas y las Entidades Locales ${ }^{24}$. Así, varios autores reconocen la naturaleza política de la autonomía local, por las características representativas y democráticas de los entes locales; sin embargo, observa que la dimensión política de los Entes Locales es menor que el de las Comunidades Autónomas ${ }^{25}$.

La jurisprudencia del Tribunal Constitucional, en la década de los 80 , sostenía que las administraciones locales contaban, únicamente, con una autonomía administrativa, porque sólo tenían capacidad para aprobar reglamentos y dictar actos administrativos, a diferencia de las Comunidades Autónomas y el Estado que sí contaban con una autonomía política consistente en la capacidad legislativa ${ }^{26}$. La condición administrativa de la autonomía local, explicitada por esta jurisprudencia, determinó que las Entidades Locales estuvieran bajo el control de los Entes Autonómicos y el Estado, siendo concebida la autonomía local como una simple "garantía institucional”².

En ese sentido, la profusa jurisprudencia del Tribunal Constitucional concibió la autonomía local como "la distribución territorial del poder del Estado en sentido amplio del término" así como "un derecho de la comunidad

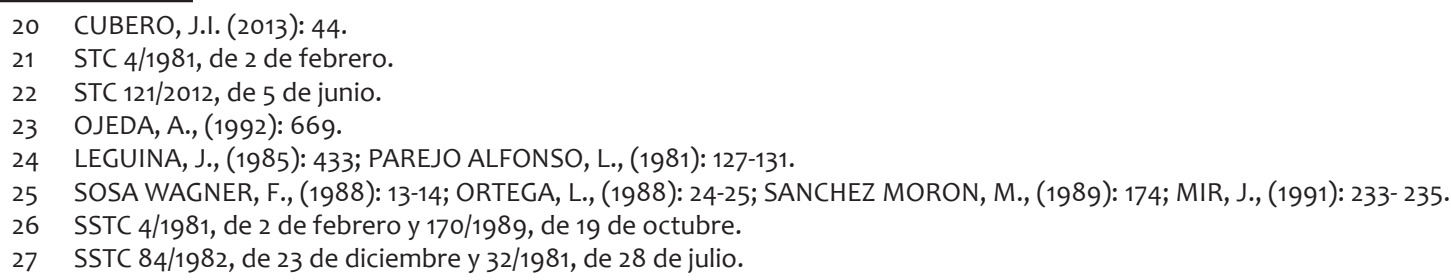


local a participar, a través de órganos propios, en el gobierno y administración de cuantos asuntos le atañen, constituyendo en todo caso un poder limitado que no podía oponerse al principio de unidad estatal”28.

Esta visión tradicional de la autonomía administrativa ha virado hacia una visión de autonomía política más adelantada, a partir de la aplicación de la normativa europea. La Carta Europea de Autonomía Local (CEAL), ratificada por España"29, define la autonomía local como "el derecho y la capacidad efectiva de las Corporaciones Locales de ordenar y gestionar una parte importante de los asuntos públicos en el marco de la ley, bajo su propia responsabilidad y en beneficio de sus habitantes" (Art. 3.1 ${ }^{\circ}$ ). Según algunos autores, los artículos 137 CE y 2.25 , 2.26 y 43.4 LRBRL deberían interpretarse de acuerdo con el Art. $3^{\circ}$ de la CEAL ${ }^{30}$, conforme al cual, las competencias no deberían ser tuteladas, controladas administrativa ni políticamente por los entes superiores (art. 4.4. CEAL). Sin embargo, esta interpretación no fue aceptada por el Tribunal Constitucional, alegando su clásica doctrina de que los Tratados Internacionales no pueden ser incluidos en el bloque de constitucionalidad ${ }^{31}$. Posteriormente es cuando se definió a la autonomía local en los términos de lo establecido por la CEAL, aunque de manera restrictiva.

La concreción del principio constitucional de autonomía local se encuentra expresado en la Ley de Bases de Régimen Local. Así, en su art. 1, reconoce la autonomía de los Municipios, Provincias e Islas en la gestión de los intereses propios de sus colectividades; y, en el art. 2, exige la atribución de competencias por parte de la legislación nacional y autonómica, para asegurar el ejercicio efectivo de la autonomía, la cual se sujeta a determinados principios tales como la descentralización, proximidad, eficacia y eficiencia, y con estricta sujeción a la normativa de estabilidad presupuestaria y sostenibilidad financiera, conforme establece su art. 2.1, reformado por la Ley 27/2013. En la primera parte del precepto, ante la ausencia de una atribución directa constitucional, se explicita la necesaria intervención legislativa para que se distribuyan las competencias. La segunda parte del precepto es la que interesa comentar, por haber sido objeto de reciente reforma y por sus efectos en la autonomía local.

En la versión original del precepto se hacía referencia a los principios de descentralización y máxima proximidad de la gestión administrativa a los ciudadanos. En la actualidad, se mantiene el principio de descentralización, pero se ha modificado el segundo principio por “proximidad”. Además de ello, se han agregado los principios de eficacia y eficiencia. Todos, sujetos a la normativa de estabilidad presupuestaria y sostenibilidad financiera.

Según la doctrina, esta transformación hacia la búsqueda de eficiencia y ahorro, permite excluir la proximidad más cercana del Gobierno Local para resolver los asuntos de la comunidad, por otro nivel de gobierno que resulte más eficiente o rentable, aunque no resulte ser el más cercano a las necesidades, problemas o intereses de la colectividad. En esas condiciones, se pretenden omitir los principios de subsidiariedad y capacidad autónoma de gestión de las Entidades Locales, que están vinculados a la máxima proximidad. Por tanto, el riesgo de la reforma es priorizar la eficiencia, el control del gasto y la estabilidad presupuestaria, al poner por debajo los principios de la conformación competencial. Los diferentes cambios, a propósito de la reforma de la Ley $27 / 2013$, consistentes en la reducción de materias, que aparecen en el art. 25.2; y, la supresión del art. 28, con relación a la competencia complementaria, dan cuenta de una minusvaloración de la autonomía local hacia una mera autonomía administrativa o de ejecución, en tanto que, esta reforma les ha colocado cortapisas a los Entes Locales para tener iniciativa en el ámbito de sus competencias ${ }^{32}$.

De lo anterior se puede colegir que la autonomía local en España se encuentra garantizada por la norma constitucional y desarrollada por el ordenamiento jurídico. La Ley Reguladora de Bases del Régimen Local es la que establece un mínimo de competencias para los entes locales; mientras, el Estado y las Comunidades Autónomas tienen facultades para dotarles de un mayor número de competencias. Sin embargo, con la reciente reforma, la autonomía local, al parecer podría ser reducida a un ámbito menor de competencias, las mismas que serán objeto de estudio, de acuerdo a los recientes cambios que han sufrido las competencias locales.

\subsection{Límites a la autonomía municipal en Perú}

Un aspecto que fortalece el papel de los gobiernos locales en el Perú es el reconocimiento constitucional de su autonomía. El art. 194 de la Constitución les atribuye una autonomía política, económica y administrativa en los asuntos de su competencia33. La jurisprudencia del Tribunal Constitucional sostiene "el carácter descentralizado del Estado peruano (... ) no es incompatible con la configuración de Estado unitario, desde el momento que si

28 SSTC 4/1981, de 2 de febrero y 32/1981, de 28 de julio, SSTC 27/1987, de 27 de febrero, STC 170/1989, de 19 de octubre, 109/1998, de 21 de mayo, y 159/2001, de 5 de julio.

29 Ratificada el 20 de enero de 1988, en vigor el 1 de marzo d 1989.

30 RODRIGUEZ ARANA, J., (1999): 339-340.

31 STC 235/2000, de 5 de octubre.

32 MELLADO RUIZ, L., (2014): 500 y ss.

33 Artículo modificado por el Artículo Único de la Ley N²8607, publicada el 04 Octubre 2005. 
bien ella supone el establecimiento de órganos de poder territorialmente delimitados, a los cuales se les dota de autonomía política, económica y administrativa, sin embargo, su ejercicio debe realizarse dentro de lo previsto por la Constitución y las leyes marco que regulan el reparto competencial de los gobiernos regionales y municipales". ${ }^{4}$

Esta autonomía se refiere a que los gobiernos municipales podrán tomar decisiones de orden político, económico y administrativo, pero únicamente en las materias que son de su competencia, por lo que, en cada caso, será importante analizar las competencias que correspondan a cada nivel municipal. Los sujetos beneficiarios de tal autonomía son las municipalidades provinciales y distritales, como se puede advertir de la redacción del citado artículo. Por tanto, el resto de municipalidades quedan desamparadas de tal atributo.

Ahora bien, la norma constitucional no define lo que se entiende por autonomía local, por lo que es necesario recurrir a la LBD. Esta norma, en su art. 8, define la autonomía como "el derecho y la capacidad efectiva del gobierno en sus tres niveles, de normar, regular y administrar los asuntos públicos de su competencia. Se sustenta en afianzar en las poblaciones e instituciones la responsabilidad y el derecho de promover y gestionar el desarrollo de sus circunscripciones, en el marco de la unidad de la nación". El alcance de la autonomía, por tanto, se encuentra limitado por el propio ordenamiento.

Como se ha advertido al inicio, el art. 194 de la CPE de 1993 les reconoce a las municipalidades provinciales y distritales tres dimensiones de autonomía: política, económica y administrativa. Para no generar una interpretación antojadiza, éstas han sido desarrolladas por la LBD, a la cual también se remite la jurisprudencia del TC. La autonomía política significa que tienen capacidad de adoptar y concordar las políticas, planes y normas en los asuntos de su competencia, aprobar y expedir sus normas, decidir a través de sus órganos de gobierno y desarrollar las funciones que le son inherentes; por la autonomía administrativa tienen la facultad de organizarse internamente, determinar y reglamentar los servicios públicos de su responsabilidad; finalmente, en la autonomía económica tienen la facultad de crear, recaudar y administrar sus rentas e ingresos propios y aprobar sus presupuestos institucionales conforme a la Ley de Gestión Presupuestaria del Estado y las Leyes Anuales de Presupuesto 35.

El Tribunal Constitucional ha establecido que "la autonomía municipal supone capacidad de autodesenvolvimiento en lo administrativo, político y económico de las municipalidades, sean estas provinciales o distritales; y que esta garantía permite a los gobiernos locales desenvolverse con plena libertad en dichos ámbitos; es decir, se garantiza que los gobiernos locales, en los asuntos que constitucionalmente le atañen, puedan desarrollar las potestades necesarias que garanticen su autogobierno" ${ }^{36}$.

Un aspecto fundamental de la autonomía es que atienda a su propósito, consistente en la satisfacción del interés de los vecinos. Al respecto, la jurisprudencia del TC sostiene que la autonomía, garantizada por la Constitución a favor de las municipalidades, debe ser ejercida buscando satisfacer el interés de los vecinos. El sustento de esta afirmación se encuentra en el rol que cumplen los gobiernos locales como instituciones representativas de los vecinos de una determinada localidad. Por tanto, las municipalidades se encuentran obligadas a brindar una adecuada prestación de servicios públicos locales, fomentar el bienestar de los vecinos y el desarrollo integral y armónico de sus circunscripciones, ajustada a las necesidades de sus pobladores ${ }^{37}$.

Corresponde apuntar que uno de los riesgos de la autonomía municipal es que puede ser vulnerada por el ordenamiento establecido a nivel del gobierno nacional, sometiendo o condicionando con ello el actuar de los gobiernos locales. Ante ello, el TC se ha pronunciado y señala que el legislador nacional puede regular el régimen jurídico de la autonomía municipal, siempre que respete su contenido esencial, es decir, que no sujete o condicione la capacidad de desenvolvimiento pleno de las municipalidades. Aclara que la autonomía no es autarquía, por lo que, la garantía institucional que se le reconoce a los gobiernos locales constituye la capacidad de autonormación y administración dentro del ordenamiento jurídico y, en particular, dentro de los límites establecidos por la Constitución. Concluye señalando que la autonomía es un poder limitado en el que se ejercita un conjunto de atribuciones, respetando el principio de unidad del Estado, referido en el art. 43 de la Carta Constitucional ${ }^{38}$.

Otra amenaza a la autonomía municipal surge producto de los conflictos de competencias entre los gobiernos locales provinciales y distritales. Ocurre que, con el objeto de invalidar las disposiciones emanadas por uno, el otro utiliza las ordenanzas omitiendo lo establecido por el artículo 200, inciso 4 de la Constitución, donde se establece que las ordenanzas tienen rango de ley, por lo que su inaplicación o invalidación sólo tiene efectos mediante control constitucional. Por tanto, los órganos constitucionales facultados para declarar inaplicables las ordenanzas

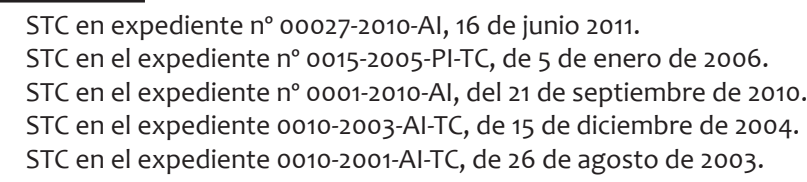


son el Poder Judicial, el Jurado Nacional de Elecciones o el Tribunal Constitucional. En ese sentido, los demás órganos, como es el caso de las municipalidades no pueden irrogarse tales facultades. Y, como se comentó antes, los conflictos competenciales no sólo surgen entre los gobiernos locales, sino también con y entre los gobiernos regionales y los sectores del Estado, debido a que la legislación no se encuentra debidamente concordada y existe posibilidad de duplicidad de funciones, por ello en la actualidad se está implementando una política destinada a delimitar las competencias entre todos los niveles de gobierno, especialmente, respecto de las competencias compartidas.

En conclusión, la autonomía local, tanto en España como en Perú, se encuentra reconocida a nivel constitucional y está reservada a los gobiernos locales territoriales. Las competencias y los recursos económicos son los presupuestos que garantizan la autonomía, por ello, son reconocidos por la regulación. En España, a través de la Ley Reguladora de Bases del Régimen Local y, la Ley Reguladora de Haciendas Locales; y, en Perú, de la Ley Orgánica de Municipalidades y la Ley de Tributación Municipal. Sin embargo, existen algunos cuestionamientos en torno a las competencias que ameritan análisis.

\section{Duplicidad de competencias y reformas al régimen local}

Las competencias locales son las atribuciones que tienen reconocidos los gobiernos locales, a través de la Constitución y las leyes, para la prestación de los servicios públicos y el desarrollo local. Tanto en España como en Perú, se han identificado problemas de duplicidad de competencias entre los distintos niveles de gobierno, ante lo cual se han adoptado variadas políticas. En España se han reformado las competencias locales y en Perú se vienen implementando mecanismos para delimitarlas. Estas reformas tienen incidencia en la autonomía local y la descentralización de ambos países.

\subsection{Reformas a las competencias locales por reducción del gasto público en España}

Las competencias locales en España no están definidas constitucionalmente, se remiten a lo establecido por la legislación del nivel nacional y de las Comunidades Autónomas. Sin embargo, en este estudio sólo se analiza la legislación estatal, para facilitar el análisis comparativo. La norma constitucional brinda una regulación general a los Entes Locales y desarrolla unos principios locales que son los pilares en los que se funda la legislación para desarrollar sus competencias. A continuación se profundiza el análisis en la Ley de Regulación Básica del Régimen Local, en especial, con relación a la reciente reforma en el ámbito competencial.

La Ley Reguladora de Régimen Local -LRBRL ${ }^{39}$, como se señaló antes, es la norma que especifica las materias vinculadas a las competencias mínimas de los gobiernos locales. Esta norma ha sido modificada recientemente, a través de la Ley 27/2013, de 30 de diciembre de 2013, con el objetivo de reorientar la situación de déficit presupuestario de España. Así, el régimen local ha cambiado, principalmente, en el ámbito competencial, con varios objetivos, entre ellos clarificar las competencias locales, para evitar duplicidades con otras administraciones del Estado. Según el nuevo modelo, se hace una precisión y reducción de las competencias propias; se introducen novedosos preceptos respecto de las competencias delegadas; y, se restringe la asunción de competencias impropias, denominadas "distintas de las propias" para las cuales se contemplan determinados requisitos. A continuación, se analiza brevemente en qué consisten estas novedades y si han logrado conseguir el objetivo planteado.

El marco general de las “competencias", contenido en el art. 25.2 LRBRL, ha sido precisado después de la reforma. Ahora alude de manera concreta a las "competencias propias" cuyas materias se encuentran anotadas en dicho artículo. Con la nueva redacción, para algunos, pareciera que estas constituyen el máximo de competencias propias a ser asumidas por los gobiernos locales, impidiéndose que las mismas puedan ser ampliadas por las CC.AA., como se regulaba hasta antes de la reforma ${ }^{40}$. Otro sector de la doctrina, en cambio, señala que este precepto contempla un ámbito material en el que se reservan competencias propias al municipio, por lo tanto se trata de competencias propias garantizadas. Adicionalmente a ellas, sostienen que las CC.AA. pueden asignarles otras competencias que estimen resulten propias para los municipios, las cuales a diferencia de las anteriores no están protegidas por una garantía básica de atribución como las primeras, pero no dejan de ser propias a tenor del art. 7.2 LRBRL ${ }^{41}$.

Para mayor fundamento, es necesario conocer cuáles son los niveles de gobierno autorizados en asignar estas competencias a las Entidades Locales y los instrumentos legales habilitantes para ello. La STC 214/1989, FJ3, declara que el Estado puede definir los "principios básicos en orden a las competencias", es decir el sistema

39 Ley Reguladora de Régimen Local, 7/1985, de 2 de abril.

40 MEDINA GUERRERO, M., (2014): 41 y 42.

41 MORILLO-VELARDE PÉREZ, J.I., en QUINTANA LÓPEZ, T. (Dir.), (2014): 85-86. 
competencial local. Sin embargo, no es competencia del Estado atribuir competencias específicas a las Entidades Locales en materias sectoriales propias de las Comunidades Autónomas. Los instrumentos legales a través de los cuales se aprueban las competencias propias son la Ley estatal y las leyes autonómicas, dentro de sus ámbitos competenciales en este último caso. Por tanto, el art. 25.2 LRBRL no contiene una lista cerrada de competencias municipales, sino más bien un listado de materias obligatorias, sobre las cuales las leyes estatales y autonómicas deben atribuir competencias específicas a los gobiernos locales. Pero, más allá de esas materias, las CC.AA. tienen capacidad, dentro del ámbito de sus competencias, de atribuirles más competencias ${ }^{42}$. Por tanto, existen unas competencias propias necesarias, atribuidas por el legislador estatal o autonómico en las materias contenidas en el art. 25.2 LRBRL; así como otras competencias propias suplementarias, atribuidas por los mismos en materias distintas a las consignadas ${ }^{43}$.

Otra reforma encontrada en el art. 25.2 LRBRL es la reducción de las materias vinculadas a las competencias propias. Concretamente, se han suprimido algunas materias -Educación, Sanidad y Servicios Sociales-, que constituían el ámbito competencial mínimo de los gobiernos locales. Así, los servicios vinculados a la protección de la salubridad pública quedan excluidos de su prestación; en sanidad desaparece como materia competencial la gestión de la atención primaria de salud; y, en servicios sociales se recorta la acción municipal. Algunos expertos ${ }^{44}$ califican esta situación como un vaciamiento de competencias, lo cual genera un choque con el principio de autonomía local, ya que estos servicios debieran ser atendidos por el nivel de gobierno más próximo a la población como son los ayuntamientos ${ }^{45}$. Sin embargo, para otro segmento de la doctrina no existe vulneración a la autonomía local, porque las materias referidas a las competencias propias necesarias pasan a formar parte de las competencias necesarias suplementarias, con lo cual no se reduce la autonomía local. Tanto más que, la LRBRL no tiene la función de atribuir competencias sino de garantizar un ámbito competencial mínimo ${ }^{46}$. Con la aclaración efectuada antes, se debe entender que, la reducción o supresión de materias del listado del art. 25.2 LRBRL, reduce la garantía funcional mínima a un menor número de materias sobre las cuales se deben entregar competencias locales, pero no restringe la posibilidad que le sean asignadas o delegadas más competencias fuera de ese marco.

El otro tipo de competencias reconocidas por la LRBRL es la delegada, a través de la cual se transfiere el ejercicio de la competencia más no la titularidad. A este respecto existen aspectos novedosos con la reforma. Estos se refieren al sentido de la delegación, restricción de los actores delegantes, el ámbito materia de delegación, el procedimiento, entre otros aspectos. El sentido de la delegación involucra una ampliación del poder local, a partir del interés no sólo estatal, autonómico, sino local. Los actores delegantes no estaban definidos antes, ahora están restringidos al Estado y las Comunidades Autónomas, con lo cual quedan excluidas otras entidades. La inclusión de un catálogo de materias delegables, aunque con un carácter orientativo, ya que en caso contrario se trataría de una limitación en el ejercicio de las competencias autonómicas. Las normas que fijan los términos de la delegación son el dispositivo o acuerdo de delegación. Se precisan algunos requisitos previos para la administración delegante. Así, se debe determinar su alcance, contenido, condiciones, duración no menor de 5 años, efectuar un control de eficiencia y contar con todos los medios (personales, materiales y económicos) necesarios para ser asignada determinada competencia. Se contempla la aceptación de la delegación efectuada por los municipios, con la cual desaparecen las delegaciones impuestas por ley.

Sin perjuicio de lo anterior, el aporte más destacado de la reforma, contenido en el apartado 6 del art. 27 LRBRL, es la imposibilidad de delegar competencias sin la financiación respectiva. La introducción de este precepto constituye una noticia positiva para los gobiernos locales, porque no tendrán que usar sus propios recursos económicos para cubrir los servicios delegados ${ }^{47}$. Finalmente, el propósito de fondo de la reforma, a través de la delegación, es reducir el gasto, para lo cual se prevé que se mejore la eficiencia de la gestión pública y se contribuya a eliminar las duplicidades administrativas ${ }^{48}$.

Finalmente, corresponde abordar las "competencias impropias", hoy denominadas "competencias distintas de las propias". A juicio del legislador, una de las causas para las disfuncionalidades del modelo competencial anterior fue que los gobiernos locales ejercían competencias que no les correspondían, pero que eran demandadas y no eran asumidas por otros niveles de gobierno. El marco normativo anterior garantizaba la asunción de estas

42 VELASCO CABALLERO, F., en ZABALLOS, D. (Coord.), (2014): 54 y 57.

43 ALMEIDA CERREDA, M., en QUINTANA LÓPEZ, T. (Dir.), (2014): 116, 130-131.

44 INSTITUTO DE ECONOMÍA DE BARCELONA (2013): 5 y ss.

45 Como dispone la Carta Europea de la Autonomía Local, ratificada por España el 20 de enero de 1988, se contempla el principio de subsidiariedad como principio básico de la autonomía local.

46 ALMEIDA CERREDA, M., en QUINTANA LÓPEZ, T. (Dir.), 2014; VELASCO CABALLERO, F., en ZABALLOS, D. (Coord.), 2014.

47 CAMPUS ACUÑA, C., y LAGO PENAS, S., (2013): 9 y ss.

48 Segundo párrafo del art. 27.1 y 27.3 LRBRL 
competencias, ya que el art. 25.1 LRBRL hacía referencia a que el Municipio podía asumir toda clase de actividades y cuantos servicios públicos fueran necesarios. Con la reforma, este precepto ha sido cambiado. Se han suprimido los términos "toda clase" y "cuantos", por tanto, estas actividades y servicios, deben atender únicamente a las competencias que les son atribuidas, con lo cual están prohibidos de atender competencias impropias como lo refiere el propio preámbulo de la Ley $27 / 2013^{49}$. Añadido a ello, se ha suprimido el art. 28 LRBRL sobre actividades complementarias, con lo cual, se cierra también esta vía de asumir más competencias de las prescritas.

A pesar de lo anterior, la Ley 27/2013, en su art. 7.4, deja abierta la posibilidad que las Entidades Locales ejerzan competencias potestativas, pero, siempre y cuando se cumplan dos supuestos: Que no se ponga en riesgo la sostenibilidad financiera de la Hacienda municipal, es decir, de las finanzas locales; y, que no exista ejecución simultanea de servicio público con otra Administración Pública. Para garantizar el cumplimiento de estos presupuestos, se refuerza la posición de las CC.AA., en tanto que, se exigen unos informes previos donde se indique que no existen duplicidades, con lo cual, la municipalidad se sujeta a las Comunidades Autónomas y se restringe su autonomía local.

Luego del análisis anterior, la valoración sobre la última reforma, en el ámbito de las competencias locales, es que no se ha cumplido del todo el objetivo previsto de clarificar las competencias y evitar las duplicidades con otras administraciones del Estado. Por una parte, se ha precisado el ámbito competencial mínimo, a través de las competencias propias y delegadas; se han suprimido las competencias impropias, para evitar las duplicidades, pero se ha admitido la existencia de una categoría de "competencias distintas de las propias", aunque con serias restricciones sometidas al control de las CC.AA.

Con el fin de reducir los costes, se han reducido las competencias propias locales, en los ámbitos de educación, sanidad y servicios sociales para ser transferidas a las CC.AA., no obstante, será el ámbito autonómico el que decida si son los Entes Locales los que continúen prestando estos servicios, a través de competencias propias suplementarias o vía delegación, con lo cual, nuevamente se refuerza el poder de las CC.AA.

Por tanto, por una parte, sí bien se ha reducido el ámbito competencial de los gobiernos locales respecto de las competencias propias necesarias; por otra, en cambio, existe incertidumbre para los ciudadanos sobre las entidades que llevarán a cabo la prestación de los servicios en las materias reducidas o suprimidas. Por consiguiente, no existen propuestas cooperativas para evitar las duplicidades con otras administraciones del Estado, sino más bien imperativas por Ley.

Este nuevo régimen de las competencias locales, si bien son más específicas; la reducción del ámbito competencial, basada en la eficiencia, podría dar lugar a una recentralización, ya que se restringen las potestades de los Gobiernos Locales y se las somete a las decisiones de las Comunidades Autónomas. Con una última reforma, se cree que, las ineficiencias del sistemas competencial no logran superarse, por cuanto, no se ha realizado una revisión completa del sistema competencial de todos los niveles de gobierno que permita avanzar desde un modelo dependiente del Estado y las Comunidades Autónomas, hacia uno más integrado y cooperativo, en la cual los tres niveles de gobierno puedan actuar de forma coordinada para satisfacer las necesidades de los $\operatorname{ciudadanos}^{50}$.

\subsection{Duplicidad de competencias locales por falta de concordancia normativa en Perú}

Uno de los problemas que presenta Perú, al igual que España, es la duplicidad de las competencias locales. La causa del problema parece simple, se trata de una falta de concordancia normativa. En determinados casos, varios niveles de gobierno gozan de las mismas competencias; y, en otros, los niveles municipales tienen dificultades para determinar sus competencias compartidas. El Estado, para corregirlo, ha implementado una serie de políticas e instrumentos, como se verá más adelante, pero no corrige de raíz el problema, porque en el ámbito local, no hay ninguna propuesta de reforma en materia competencial.

La Constitución Política de 1993 se detiene en concretar un conjunto de materias de competencia a los Gobiernos Locales y, al mismo tiempo, les reconoce suficiente autonomía local. Sin embargo, sólo lo hace a favor de las municipalidades provinciales y distritales. Las materias competenciales se desprenden del contenido del Título IV “de la estructura del estado” y el capítulo XIV “de la descentralización”. Por tanto, los gobiernos locales disponen de un campo de actuación constitucionalmente reconocido y delimitado frente al nivel estatal y regional. Así lo reconoce el TC, sostiene "el carácter descentralizado del Estado peruano (...) no es incompatible con la configuración de Estado unitario, desde el momento que si bien ella supone el establecimiento de órganos de poder territorialmente delimitados, a los cuales se les dota de autonomía política, económica y administrativa, sin

49 "Las Entidades Locales no deben volver a asumir competencias que les atribuye la Ley y para las que no cuenten con la financiación adecuada”.

50 ARENILLA, SÁEZ, M., (2013): 48-52.

REALA, n 3, enero-junio 2015, ISSN: 1989-8975 - DOI: http://dx.doi.org/10.24965/reala.v0i3.10251 
embargo, su ejercicio debe realizarse dentro de lo previsto por la Constitución y las leyes marco que regulan el reparto competencial de los gobiernos regionales y municipales" ${ }^{\prime 1}$.

Las competencias reconocidas a nivel constitucional se encuentran definidas en el art. 195. Esto significa que ninguna norma de rango inferior puede reducir las competencias allí reconocidas. El legislador afirma, a modo de objetivos, que los gobiernos locales promueven el desarrollo y la economía local, así como la prestación de los servicios públicos bajo su responsabilidad, en armonía con las políticas y planes nacionales y regionales de desarrollo. Para el cumplimiento de esos objetivos, el referido artículo les reconoce diez competencias que comprende aspectos administrativos internos, potestades a nivel tributario y normativo, además de otras cuestiones.

Como se anunció al inicio de este apartado, la Constitución reconoce la autonomía de las Municipalidades provinciales y distritales, en las materias de su competencia. Por lo tanto, la autonomía constituye un blindaje que brinda protección a las entidades locales, en las competencias especificadas en el art. 195 de la Norma Constitucional y desarrolladas en la Ley Orgánica de Municipalidades-LOM. Se trata, por tanto, de una institución que garantiza el cumplimiento de las competencias y funciones de los Gobiernos Locales, ya que éstos tienen efecto en el bienestar de la comunidad.

Si bien la LOM desarrolla las competencias específicas y compartidas de las municipalidades provinciales y distritales, esta desagregación no es muy clara. El problema se halla en la dualidad municipal (provincial y distrital), es decir, en la complejidad del reparto de competencias, ya que el tratamiento de las competencias es general y ambiguo, no se explicitan las que corresponden a cada cual, especialmente, cuando se trata de las competencias compartidas.

Para entender de mejor forma esta cuestión, conviene revisar alguna de las competencias que establece la Constitución y la Ley Orgánica de Municipalidades-LOM, en relación con una materia. Así, en materia de salud, es “exclusiva o compartida" para las Municipalidades Provinciales o Distritales ${ }^{52}$. Si bien, en la LOM, se definen las competencias específicas y las compartidas, sólo se explicitan las específicas para cada tipo de municipalidad y se omiten las compartidas 53 . Por tanto, en este último caso, resulta difícil diferenciar las competencias cooperativas que corresponden a cada tipo de municipalidad, con lo cual se podrían duplicar las acciones que realicen ambas municipalidades por separado. Este riesgo se acrecienta en caso de no existir coordinación interinstitucional.

Ante esta cuestión, la Defensoría del Pueblo, el año 2008, expresó que ésta no es la única observación que presenta la aplicación de la LOM. La forma en que define esta norma las competencias locales genera conflictos con otros niveles de gobierno. Así ocurre, cuando se pretenden diferenciar las competencias locales de las regionales y sectoriales. Existe conflicto de competencias entre las normas sectoriales y las descentralizadoras ${ }^{54}$. Para contrastar esta hipótesis, conviene examinar las normas que regulan las competencias locales.

Entre las principales normas que actualmente rigen las competencias de las municipalidades, después de la Constitución, se encuentran la Ley de Bases de la Descentralización-LBD ${ }^{55}$ y la Ley Orgánica de Municipalidades-LOM ${ }^{56}$. Las competencias que éstas recogen son obligatorias para los gobiernos locales. Así, el Tribunal Constitucional, en uno de sus pronunciamientos, establece que estas competencias son indisponibles e irrenunciables, tanto para el legislador como para las municipalidades en los asuntos de su competencia y dentro de su jurisdicción ${ }^{57}$.

Los cometidos que deben cumplir las municipalidades, a decir de la vigente LOM, en las materias de su competencia son: promover, normar, regular, ejecutar, fiscalizar y controlar ${ }^{58}$. La LBD se encarga de definir los tipos de competencias y los criterios de asignación de las mismas; mientras, la LOM tiene la misión de distribuir las competencias municipales de acuerdo a la jurisdicción provincial o distrital, con precisión de los niveles y funciones ${ }^{59}$. Las competencias son clasificadas en exclusivas, compartidas y delegables, pero sólo se explicitan las primeras, dirigidas a las municipalidades provinciales y distritales. Al tratarse de las competencias exclusivas, éstas además se pueden delegar entre las propias municipalidades o a otras entidades del Estado, en los casos en que se justifique la necesidad de brindar a los vecinos un servicio oportuno y eficiente, o por economías de escala ${ }^{60}$.

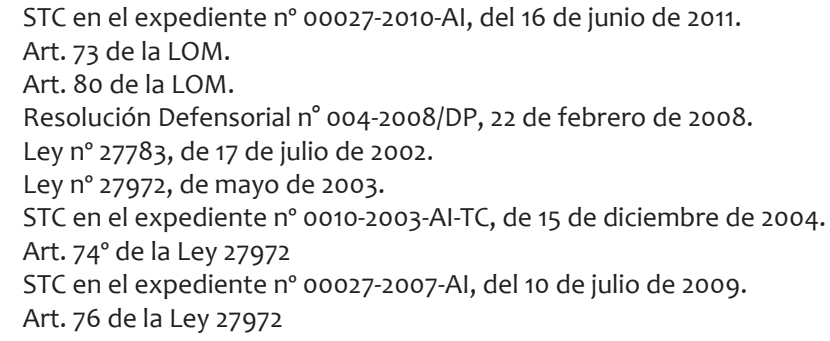


Consiguientemente, las municipalidades provinciales y distritales tienen asignadas competencias exclusivas y compartidas; los centros poblados tienen las delegadas; y las municipalidades bajo otros regímenes especiales acceden a las competencias diferenciadas.

La asignación y transferencia de competencias se rige por los cuatro criterios de asignación: subsidiariedad, selectividad y proporcionalidad, provisión y concurrencia. De todos ellos, el más idóneo a los Gobiernos Locales es el de subsidiariedad. Se funda en que el gobierno más cercano a la población, es decir, el que tiene máxima proximidad con la comunidad, es el más idóneo para ejercer la competencia. La selectividad y proporcionalidad privilegia la capacidad de gestión efectiva de los niveles de gobierno. La provisión exige que la transferencia de competencias venga acompañada de los recursos necesarios y suficientes a fin de que los servicios resulten eficientes; y, finalmente, la concurrencia, indica que todos los gobiernos deben actuar de manera eficiente, en el momento oportuno, es decir, de acuerdo a las tareas encomendadas. Este último criterio es aplicable a las competencias compartidas. Sin embargo, en la realidad parece que no se emplea a cabalidad, por la falta de delimitación de las competencias de los distintos niveles de gobierno.

Las dificultades que presenta la Ley Orgánica de Municipalidades en el reparto de competencias, son a nivel municipal como de otros niveles de gobierno. En el ámbito municipal, al existir una dualidad provincial y distrital, en algunas materias no se distinguen las competencias específicas compartidas y exclusivas para cada nivel; en otras materias, en cambio, se establece una formulación genérica de funciones donde no se asigna ningún responsable concreto, pudiéndolo asumir cualquiera de los niveles municipales. Finalmente, el reparto competencial con los otros niveles de gobierno se sostiene en la desarticulación de funciones que existe a nivel normativo, para que puedan asumir competencias los tres niveles de gobierno (nacional, regional y municipal), principalmente, cuando se trata de competencias compartidas ${ }^{61}$.

Un potencial conflicto de competencias compartidas se podría dar en torno a la gestión educativa. La participación en la gestión educativa es una de las competencias compartidas entre los niveles de gobierno local, regional y nacional ${ }^{62}$. De acuerdo a la LOM, esta materia contiene veinte funciones a ser compartidas entre los tres niveles de gobierno. Al hacer un análisis comparativo de las funciones atribuidas por la LOM y la Ley General de Educación, éstas resultan iguales para las Municipalidades y los Gobiernos Regionales, a través de las Unidades de Gestión Educativa Descentralizadas. Esto significa que, no se encuentran debidamente delimitadas las competencias entre estos niveles de gobierno. Por tanto, la aplicación de la regulación puede generar efectos perversos al momento del ejercicio de las funciones que hagan estas instancias, ya que pueden excederse en su autonomía y/o duplicar acciones o servicios.

Una explicación a esta problemática la otorga la Defensoría del Pueblo. Afirma que la debilidad del reparto competencial tiene su base en la etapa previa al último proceso de descentralización, iniciado el año 2000 . La situación ideal hubiera sido que una vez aprobada la reforma de la Constitución de 1993, respecto del capítulo XIV, Tïtulo IV, sobre descentralización, se aprobara de forma articulada todo el marco normativo descentralizador (Ley de Descentralización, Ley Orgánica del Poder Ejecutivo, Ley Orgánica de Gobiernos Regionales y la Ley Orgánica de Municipalidades). Esto no ocurrió, el proceso de descentralización se inició con la Ley Orgánica del Poder Ejecutivo que no contenía las funciones que corresponden a cada sector de gobierno, sino que se remitía a las Leyes de Organización y Funciones de cada sector; y, con la LOM no ajustada al nuevo modelo de Estado descentralizado ${ }^{63}$. En la actualidad, sólo algunos sectores han realizado la tarea de discriminar las competencias compartidas con todos los niveles de gobierno, las mismas que se hallan contenidas en sus Leyes de Organización y Funciones. En otros sectores, en cambio, la falta de delimitación de competencias continúa, con lo cual persisten los potenciales conflictos de competencias.

Esta situación se repite a nivel municipal, entre el nivel provincial y distrital. Como se enunció líneas arriba, uno de los problemas se encuentra en la forma general en la cual están establecidas sus competencias en la Ley Orgánica de Municipalidades. Ello dificulta determinar las facultades específicas que corresponde a cada nivel (provincial y/o distrital) respecto de una misma competencia. Esta problemática se evidencia en los servicios públicos locales de saneamiento, salubridad y salud ${ }^{64}$.

Otra observación advertida en la LOM es que no distingue entre competencias específicas exclusivas y compartidas de los niveles provinciales y distritales ${ }^{65}$. Particularmente, esto ocurre en las competencias en materia

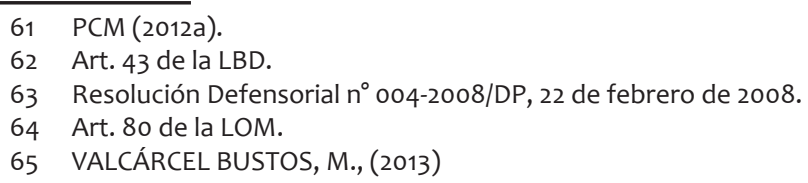


de educación, cultura, deporte y recreación ${ }^{66}$. Las competencias específicas son establecidas por la norma, pero no se señala a qué nivel de gobierno le corresponde asumir, con lo cual, lo pueden hacer indistintamente las municipalidades provinciales y/o distritales. Lo único que queda claro es que en defecto de las distritales lo deben llevar a cabo las provinciales. En esas condiciones, la LOM deja a criterio de las municipalidades la definición de responsabilidades o cómo compartir las mismas. En estas mismas materias de Educación, Cultura y Deporte existe otro problema de distribución de competencias con los Gobiernos Regionales (Unidades del Gobierno Regional) y las Municipalidades, ya que, tanto la LOM como la Ley General de Educación les asignan las mismas funciones. Por tanto, su aplicación puede generar una duplicidad de esfuerzos, así como conflictos de competencias entre los gobiernos regionales y municipales, por la falta de concordancia de la LOM con la Ley General de Educación.

En forma preventiva, para hacer frente a estos posibles conflictos de competencias, la Defensoría del Pueblo propuso que el Gobierno Nacional, los Gobiernos Regionales y los Municipales hagan una evaluación de las deficiencias encontradas en el reparto de competencias para proponer alternativas de solución, a fin de evitar futuros conflictos de competencias que perjudiquen el proceso de descentralización ${ }^{67}$.

Ante ese desafío, la Secretaría de Descentralización de la Presidencia del Consejo de Ministros, el Congreso de la República y otros sectores de la sociedad civil, han elaborado una serie de estudios y balances de la descentralización ${ }^{68}$. Entre los problemas identificados, en el ámbito de la descentralización administrativa, se encuentra la falta de claridad de las competencias de los tres niveles de gobierno. Para resolverlo se ha formulado el objetivo de "mejorar la asignación de competencias en los tres niveles de gobierno, evitando la duplicidad de funciones y recursos, y la elusión de responsabilidades en la prestación de los servicios". Para hacer efectivo este objetivo se han impulsado varias acciones.

Entre los años 2007-2012, se determinó que los ministerios elaborasen Leyes de Organización y FuncionesLOF, donde se contemplaran las funciones compartidas, pero no fue completada por todos los sectores ${ }^{69}$. Para implementar las LOF, se previó construir matrices de delimitación de competencias por cada ministerio, para clarificar las competencias que corresponden a cada nivel de gobierno, pero han tenido limitaciones en su aplicación ${ }^{70}$. Para ello, cada sector debía aprobar su Plan Anual de Transferencia de Competencias Sectoriales a los Gobiernos Regionales y Locales, donde se introdujese el enfoque de desarrollo de la gestión descentralizada de los bienes y servicios públicos que involucraba competencias compartidas entre los diferentes niveles de gobierno. Los resultados permitirían identificar el ámbito de competencia y las duplicidades existentes con otros niveles de gobierno. A partir de allí, en función de la existencia de superposición de funciones entre una entidad y un órgano de un ministerio, el Poder Ejecutivo podría definir la estructura organizacional del mismo para su adecuado funcionamiento ${ }^{71}$.

Consideramos que hace falta una reforma a la Ley Orgánica de Municipalidades, respecto de la duplicidad de competencias existentes entre los distintos niveles de gobierno local. De esta forma se evitarían los conflictos de competencias y se tendría más claridad de lo que les corresponde hacer a las municipalidades provinciales y distritales. Sin embargo, no hay ninguna propuesta en el legislativo para lograr esta reforma.

Cabe advertir que, en la actualidad, no existe una hoja de ruta que delimite las responsabilidades de cada nivel de gobierno, conforme a lo establecido por la Constitución Política del Perú, Ley de Bases de la Descentralización, Ley Orgánica de Gobiernos Regionales, Ley Orgánica de Municipalidades y leyes específicas de cada sector. Por tanto, se espera que con el esfuerzo efectuado por los ministerios y estos niveles sub-nacionales se delimiten las competencias locales y regionales; y una vez determinadas las superposiciones establecidas en la Ley Orgánica de Gobiernos Regionales y la Ley Orgánica de Municipalidades, que en determinados casos impiden determinar la responsabilidad de cada nivel de gobierno, se puedan realizar las modificatorias que correspondan.

En suma, se espera que con la política nacional de delimitación de las competencias compartidas, entre los sectores del Estado y los gobiernos locales, se resuelva parte de la debilidad competencial que enfrentan los gobiernos locales. Quedarán pendientes aquellas procedentes de la redacción de las normas municipales, como es la LOM, por la forma genérica de las competencias o por la falta de precisión de las competencias compartidas entre los niveles provinciales y distritales.

66 Art. 82 de la LOM.

67 Resolución Defensorial nº04-2008/DP, 22 de febrero de 2008

68 CONGRESO DE LA REPÚBLICA DE PERÚ (2012b); PCM (2011); PCM (2012).

69 Los ministerios que tienen su LOF son Agricultura, Ambiente, Cultura, Mimdes, Producción, Transporte y Comunicaciones; y, Trabajo y Promoción del Empleo.

70 D. S n ${ }^{\circ}$ 002-2010-TR, que aprueba la Matriz de Delimitación de Competencias y Asignación de Funciones de los sectores Trabajo y Promoción del Empleo en los tres niveles de gobierno, 10/04/10; D.S nº19-2011-MTC, que aprueba la Matriz de Delimitación de Competencias y Distribución de Funciones de los sectores Transportes y Comunicaciones en los niveles de gobierno nacional, regional y local, $13 / 05 / 2011$.

71 PCM (2010):17 


\section{CONCLUSIONES}

En Perú y España, la descentralización se ha dirigido tanto a los gobiernos locales como regionales. La experiencia española sobresale respecto de la peruana, principalmente, en el ámbito regional, por la maduración del proceso de descentralización; y, la autonomía política conseguida por los gobiernos regionales o Comunidades Autónomas. Si bien, el ámbito local no tiene igual recorrido que el regional, ha logrado importantes conquistas vinculadas a la autonomía municipal y a las competencias locales.

Ambos países han reconocido la autonomía local a nivel constitucional y, para garantizarla, les han reservado competencias y recursos a los gobiernos locales. En cuanto a competencias locales, en España, están contempladas en la Ley Reguladora de Bases del Régimen Local; mientras, en Perú es la propia Constitución la que la establece y la legislación específica la desarrolla. Esta previsión, que podría parecer mera formalidad, constituye una garantía para los gobiernos locales, ya que la jerarquía que posee la Constitución por sobre todas las leyes les brinda una mayor protección. Quizás, por ello le fue sencillo para el legislador español reformar el ámbito competencial municipal, al estar contemplado en una Ley y no en la Constitución. La regulación en materia de recursos, en España está establecida en la Ley Reguladora de Haciendas Locales y en Perú en la Ley de Tributación Municipal.

A pesar de la diferencia de garantías, una preocupación común es el diferente tratamiento otorgado a los gobiernos locales, en tanto que sólo algunos tienen reconocido el atributo de la autonomía local. Así, en España están dirigidas a favor de los Municipios, Provincias e Islas; y, en Perú, están reservadas a las municipalidades provinciales y distritales. Ello significa que el resto de gobiernos locales sólo gozan del atributo de la descentralización administrativa, es decir, que no tienen capacidad de decisión, sino sólo de ejecución.

La materia competencial resulta trascendente porque ha sido cuestionada y se han formulado reformas. La cuestión identificada, en ambos países, es la falta de claridad de las competencias municipales, lo que da lugar a duplicidades y solapamientos competenciales con otros niveles de gobierno. Se debe aclarar que los factores que han Ilevado a este escenario son distintos. En España lo ha generado la crisis económica y su afán de reducir el gasto público, que constituyen la base de la Ley 27/2013. En Perú, en cambio, los conflictos de competencias, es a raíz de la falta de concordancia del marco normativo actual, lo que ha dado lugar a políticas dirigidas a delimitar las competencias.

En el caso de España, el aspecto que resulta cuestionado sobre la reforma a la Ley Reguladora de Bases del Régimen Local es el efecto que genera sobre la autonomía local. Se han hecho ajustes profundos a las competencias locales: se especifican las competencias propias, se reduce el ámbito competencial propio y se restringe la autonomía local. En cambio, en Perú, el problema es que el proceso de descentralización, retomado la década del 2000, después de la reforma de la Constitución de 1993, comenzó de arriba hacia abajo. Primero se aprobó la Ley Orgánica del Poder Ejecutivo, sin contar con las funciones que correspondían a cada sector, ni con la adecuación de la nueva Ley Orgánica de municipalidades al nuevo proceso descentralizador. En esas condiciones, existe una duplicidad de competencias, incluso entre las propias municipalidades. Para resolverla, desde el año 2007 se están implementando instrumentos normativos, para delimitar las competencias compartidas entre los sectores del Estado, los gobiernos regionales y los gobiernos locales, a fin de clarificar las competencias, pero aún no existen resultados exitosos. Ante ello, convendría que, al menos, en el ámbito municipal, se reforme la Ley Orgánica de Municipalidades para clarificar o especificar las competencias de cada nivel municipal, pero no existen propuestas legislativas.

Se debe reconocer que la legislación del Régimen Local de España es más avanzada que la peruana. Las competencias que les otorgan a los gobiernos locales son de mayor calado, pero lo eran mucho más antes de la reforma. Les daban mucha más apertura para atender todos los bienes y servicios que demandaba la ciudadanía.

Afortunadamente, las competencias locales en España no sólo dependen de lo que establezca la Ley del gobierno central, sino de las atribuciones que les confieran las Comunidades Autónomas. De esa forma, se garantiza que sus competencias se ensanchen, para seguir conociendo las materias suprimidas, ya sea como competencias propias suplementarias o como competencias delegadas. Situación que no ocurre en Perú, ya que las competencias locales dependen exclusivamente de lo establecido por el gobierno central.

Ante este panorama, para enfrentar las ineficiencias en el reparto competencial, en Perú, es necesario que, después de culminar con la delimitación de competencias de los tres niveles de gobierno, se haga una reforma en la Ley Orgánica de Municipalidades. Sin reducir las competencias, reconocidas a nivel constitucional, hace falta precisar las competencias que corresponden a cada nivel de gobierno local, en especial las compartidas, a fin de evitar los conflictos de competencias en el nivel provincial y distrital. Todo con el propósito de asegurar el fortalecimiento de la descentralización y la autonomía local.

\section{BIBLIOGRAFÍA}

REALA, no 3, enero-junio 2015, ISSN: 1989-8975 - DOI: http://dx.doi.org/10.24965/reala.v0i3.10251 
ALMEIDA CERREDA, M., (2014). "La redelimitación de las competencias de los municipios en materia de educación, sanidad, salud y servicios sociales y su transferencia parcial a las comunidades autónomas”, en QUINTANA LÓPEZ, T. (Dir.), La reforma del régimen local, tirant lo banch, Valencia.

ÁLVAREZ, J.L. y MOLERO, J.C., (2011) “Federalismo fiscal y descentralización: España, un caso atípico, en Círculo de empresarios, Como reformas las administraciones territoriales, Madrid.

ARAGON REYES, M., “La construcción del Estado autonómico”, Cuadernos constitucionales de la Cátedra Fadrique Furió Ceriol, $n^{\circ}$ 54-55, 2006, pp. 87-88.

ARENILLA, SÁEZ, M., (2013) “El nuevo sistema de competencias locales”, en SANTA MARIA PASTOR, J.A. (Coord.) La reforma de 2013 del régimen local español, Fundación Democracia y Gobierno Local, Barcelona.

BLUME FORTIN, E. (2006) “La Descentralización en la Constitución del Perú, derecho constitucional para el siglo XXI”, actas del VIII Congreso Iberoamericano de Derecho Constitucional, Vol. 2.

CAAMAÑO DOMíNGUEZ, F., (2004) “Autonomía local y constitución, dos propuestas para otro viaje por el callejón del gato”, Revista Española de Derecho Constitucional, Año 24, nº 70, Enero-Abril.

CAMPUS ACUÑA, C., y LAGO PENAS, S., (2013) “La necesaria (y fallida reforma de la Administración local” en INSTITUTO DE ECONOMÍA DE BARCELONA, Informe IEB sobre Federalismo y Finanzas Públicas, Barcelona.

CLAVERO ARÉVALO, M. F., (1999) “Organización territorial del Estado desde 1950 al 2000", Revista de Administración Pública, $\mathrm{n}^{\circ}$ 150, Septiembre-diciembre.

CONGRESO DE LA REPÚBLICA DE PERÚ, (2012a) “Evaluación del proceso de descentralización a 10 años de su inicio" Informe Anual 2012-2013, Lima.

CONGRESO DE LA REPÚBLICA DE PERÚ, (2012b), Brújula de la descentralización 2012-2013, USAID PERU, Prodescentralización.

CUBERO MARCOS, J.I. (2013) “Efectos y alcance de las medidas anticrisis en el ejercicio y desenvolvimiento de la autonomía local”, Revista Vasca de Administración Pública, nº 95, enero-abril. Madrid.

EL CONSULTOR DE LOS AYUNTAMIENTOS Y DE LOS JUZGADOS: Nuevo Régimen Local, (1988) Vol. I, Abella,

INSTITUTO DE ECONOMÍA DE BARCELONA (2013) Informe IEB sobre Federalismo y Finanzas Públicas, Barcelona.

LEGUINA, J., (1985) “La autonomía de Municipios y Provincias en la nueva Ley Básica del Régimen Local”, Revista de Estudios de la Administración Local y Autonómica, n²27.

MEDINA GUERRERO, M., (2014) La reforma del régimen local, Tirand lo Blanch, Valencia.

MELLADO RUIZ, L., (2014) “Consecuencias derivadas de la supresión del principio de mayor proximidad”, El Consultor de los Ayuntamientos y de los Juzgados, $n^{\circ}$ 5, Sección Colaboraciones, Quincena del 15 al 29 de mar. 2014 .

MIR, J., (1991) El sistema español de competencias locales, Marcial Pons, Madrid.

MIR, J., (1987) Cuaderno Municipal: Ley Reguladora de las Bases del Régimen Local, Instituto de Estudios de Administración Local, Madrid.

MORILLO-VELARDE PÉREZ, J.I., (2014) “Las competencias de las entidades locales”, en QUINTANA LÓPEZ, T. (dir.), La reforma del régimen local, tirant lo Blanch, Valencia.

OJEDA, A., (1992) “El ámbito de la autonomía financiera en las provincias y municipios”, Revista de Estudios de la Administración Local y Autonómica, n² 255-256.

ORTEGA, L., (1988) El Régimen Constitucional de las Competencias Locales, Instituto Nacional de Administración Pública, Madrid.

PCM (2012a) Plan Nacional de Descentralización 2012-2016, Presidencia del Consejo de Ministros, Lima.

PCM (2012b) Resumen del Estado Situacional de la transferencia de competencias y funciones, fondos, programas, proyectos y activos a los gobiernos regionales y locales, Presidencia del Consejo de Ministros, Lima.

PCM (2011) Informe Anual del Proceso de Descentralización, Presidencia del Consejo de Ministros, Lima. 
PCM (2010) Memoria del proceso de implementación de la Ley Orgánica del Poder Ejecutivo, Lima.

PAREJO ALFONSO, L., (1981) Garantía institucional y autonomías locales, Instituto de Estudios de Administración Local, Madrid.

SANCHEZ MORON, M., (1989) La autonomía local. Antecedentes históricos y significado constitucional, Cívitas, Madrid.

SOSA WAGNER, F., (1988) “La autonomía local”, Revista de Estudios de la Administración Local y Autonómica, $n^{\circ} 239,1988$.

RODRIGUEZ ARANA, J., (1999) “El Pacto Local”, Revista Vasca de Administración Pública, nº 54.

VALCÁRCEL BUSTOS, M., (2013) Tesis Doctoral: “Avances y límites jurídicos a la autonomía tributaria en el Perú, a la luz de la experiencia española. Especial referencia a las tasas, contribuciones e impuestos”, Universidad del País Vasco.

VELASCO CABALLERO, F., (2014) "La ley de racionalización y sostenibilidad de la administración local en el sistema de derecho local”, ZABALLOS, D. (Coord.), Reforma del Régimen Local. 
